\title{
Advanced Imaging Techniques in Lhermitte-Duclos Disease (LDD): A Case Report and Brief Literature Review
}

\author{
N. J. Delgado, A. S. Lessa*, T. H. L. Carmo, G. M. Dias, E. J. A. Valadares, L. C. Campos, V. M. Vilela \\ Division of Radiology and Diagnostic Imaging, Universitary Hospital of the Federal University of Juiz de Fora, Juiz de Fora, Brazil \\ Email: *andreiadeseixaslessa@gmail.com
}

How to cite this paper: Delgado, N.J., Lessa, A.S., Carmo, T.H.L., Dias, G.M., Valadares, E.J.A., Campos, L.C. and Vilela, V.M. (2017) Advanced Imaging Techniques in Lhermitte-Duclos Disease (LDD): A Case Report and Brief Literature Review. Neuroscience \& Medicine, 8, 1-7. https://doi.org/10.4236/nm.2017.81001

Received: November 15, 2016

Accepted: March 25, 2017

Published: March 28, 2017

Copyright $\odot 2017$ by authors and Scientific Research Publishing Inc. This work is licensed under the Creative Commons Attribution International License (CC BY 4.0).

http://creativecommons.org/licenses/by/4.0/

\begin{abstract}
Lhermitte-Duclos disease (LDD), also called dysplastic gangliocytoma of the cerebellum, is a rare condition described in 1920. It represents a disorganization of cerebellar architecture with overgrowth of cerebellar ganglion cells which replace granular cells and Purkinje cells. In this report we present the case of a 62-year-old male affected by this disease, as well as literature review of the clinical, morphological and functional radiological findings.
\end{abstract}

\section{Keywords}

Lhermitte-Duclos Disease, Displastic Gangliocytoma, Central Nervous System, MRI

\section{Introduction}

Lhermitte-Duclos disease (LDD) is an extremely rare condition, first described in 1920 by Jacques Jean Lhermitte and P. Duclos, usually diagnosed in young adults between the 3rd and 4th decades of life, with about 221 cases reported in the literature to this date. It consists of a cerebellar lesion of uncertain nature known as the cerebellar dysplastic gangliocytoma, characterized by overgrowth of cerebellar ganglion cells which replace granular cells and Purkinje cells [1]. MRI high-field imaging with advanced features is considered as the method of choice for diagnosis, safely eliminating the main differential diagnosis and avoiding unnecessary invasive diagnostic procedures.

\section{Case Report}

We reported the case of a 62-year-old male who presented with unilateral tinnitus on the right side, without other symptoms (Table 1). 
The Ear, Nose and Throat (ENT) assessment and the neurological examination were normal.

Magnetic resonance imaging (MRI) sequences showed an oval area with abnormal signal and morphology on the left cerebellar hemisphere, displaying linear bands with low signal intensity on T1, high signal on T2 (Figure 1) and no enhancement following administration of Gadolinium-DTPA (Figure 2).

Table 1. Sociodemographic and clinical characteristics.

\begin{tabular}{cc}
\hline Age & 62 years \\
\hline Gender & Male \\
Ethnicity & White \\
Symptoms & Unilateral tinnitus on the right side \\
\hline
\end{tabular}

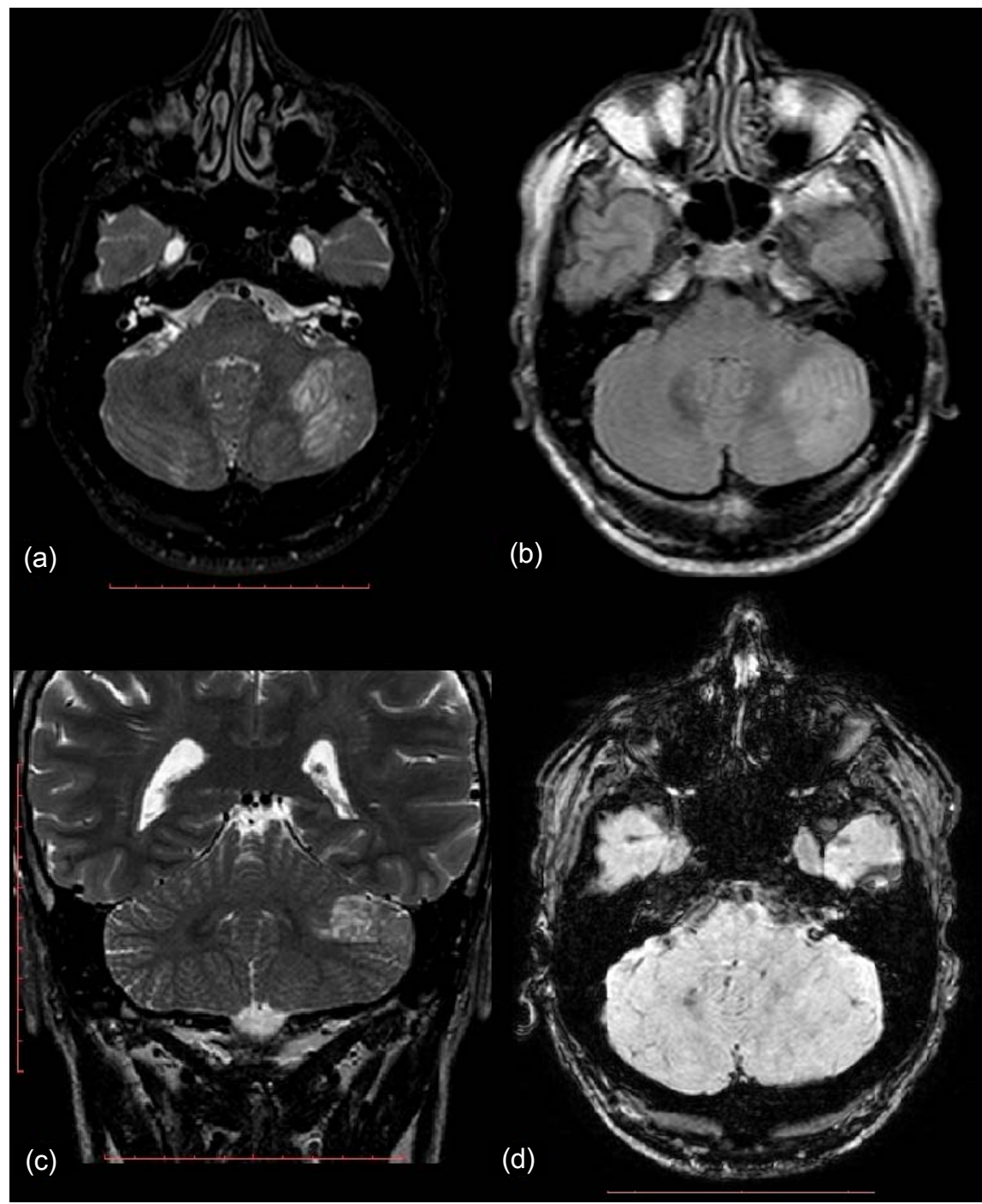

Figure 1. Axial and coronal T2 weighted images (a, c), axial FLAIR (b) and SWI sequence (d). The lesion is hyperintense and presents parallel iso/hypointense streaks related to the thickening of cerebellar folia, giving the appearance of "tiger-striped". SWI sequence shows unchanged vascular path inside the injured area. 
These area (Figure 3) presented hyperintensity on diffusion-weighted and on apparent diffusion coefficient maps, that has been attributed to T2 shine through. The susceptibility weighted imaging (SWI) sequence (Figure 1) showed unchanged vascular path inside the injured area. Perfusion study revealed no areas of increased CBV that could mean neoangiogenesis tumor (Figure 4). The spectroscopy of single voxel proton focused on cerebellar parenchyma alteration showed no change on the peaks of myo-inositol, $\mathrm{N}$-acetyl aspartate (NAA), creatinine (Cr) and cholin (Cho) (Figure 5).

Based on the clinical and MRI findings, the diagnosis of Lhermitte-Duclos was assumed. The patient was followed up for six months, having died due to other causes.

\section{Discussion}

Dysplastic cerebellar gangliocytoma is a solid cerebellar lesion, with an expansive aspect, typically unilateral, with no gender preference and a few cases reported in children [2] [3].

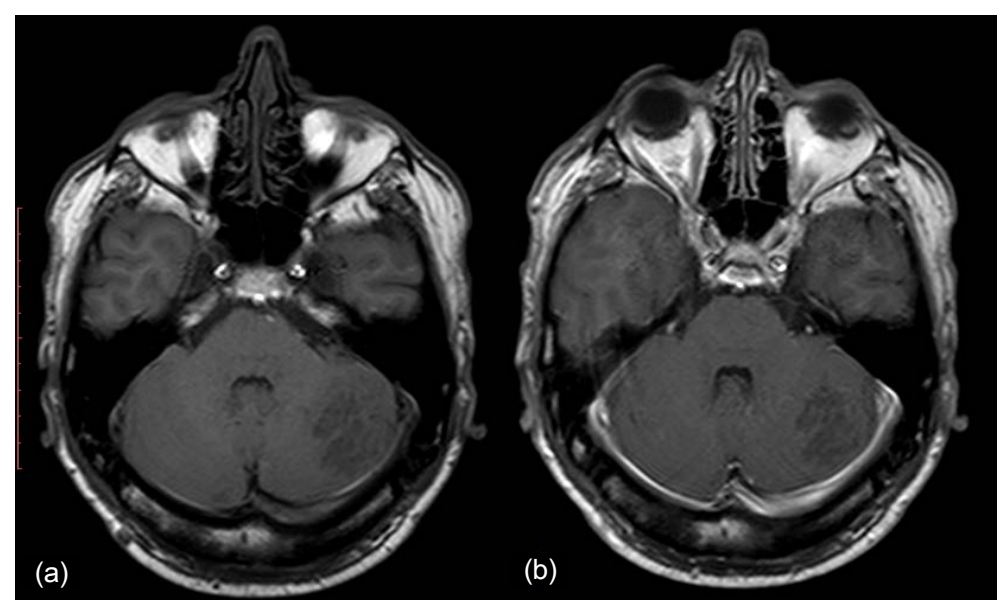

Figure 2. Pre (a) and post-contrast (b) axial T1-weighted images, demonstrating the absence of contrast enhancement.

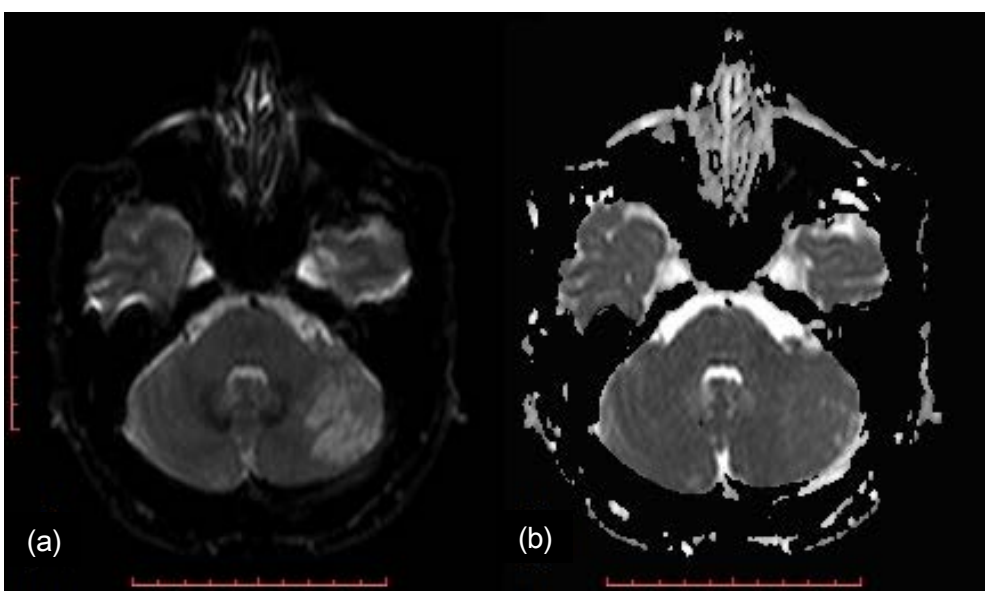

Figure 3. (a) Diffusion weighted imaging and ADC (b) don't demonstrate restricted diffusion. 


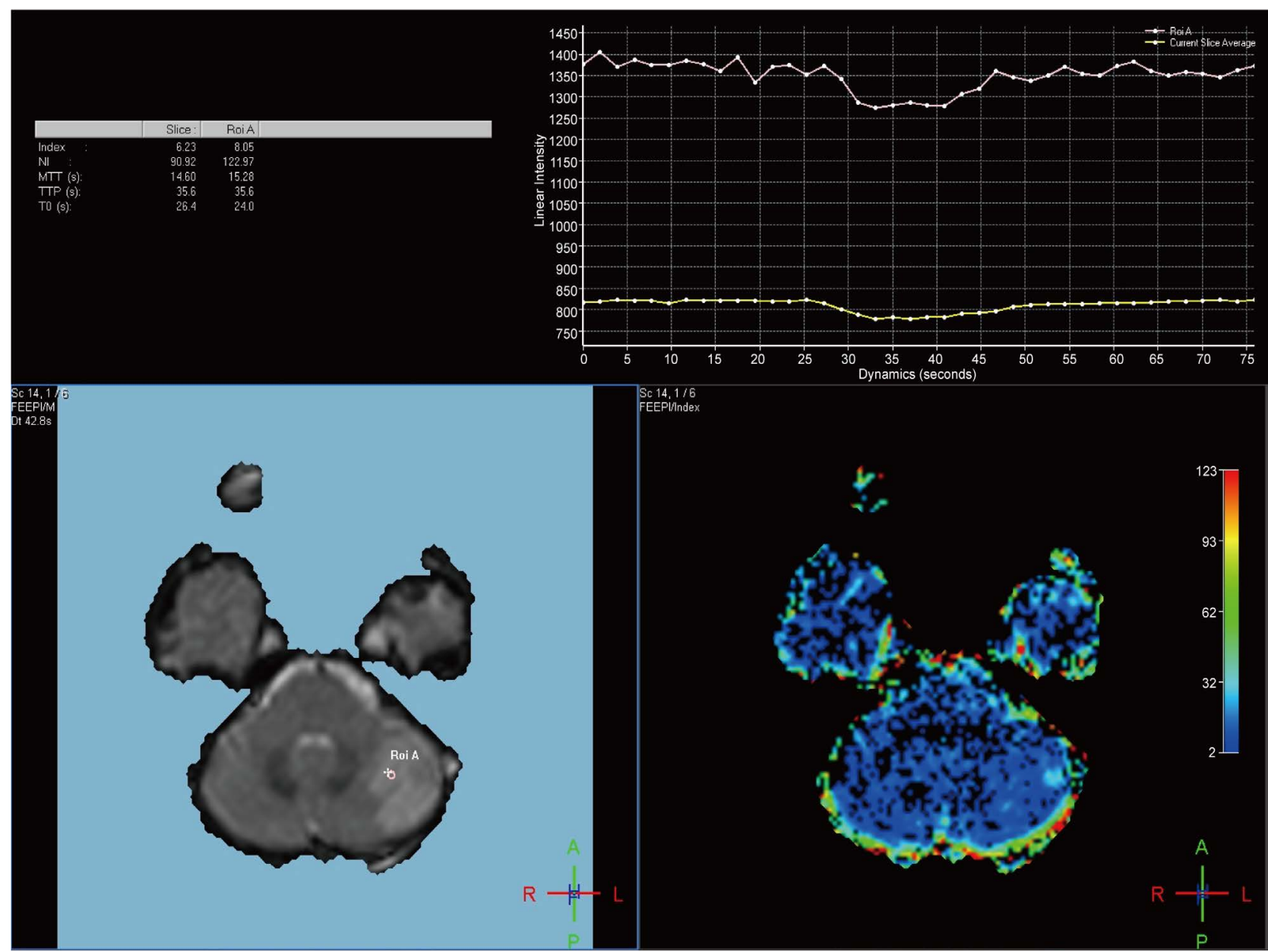

Figure 4. Perfusion study does not show increased perfusion areas.

Clinical picture is presented as asymptomatic lesion (examination found) or by symptoms resulting from the local multiplier effect, with consequent hydrocephalus (the 4 th ventricle compression), intracranial hypertension and progressive vestibular-cerebellar symptoms [4]. The patients can present with symptoms of ataxia, headache, cranial nerve dysfunction, paroxysm of vertigo, psychic deterioration and, in severe cases, signs and symptoms of intracranial hypertension secondary to hydrocephalus [5]

The cause of this disease is considerable controversial: it may have a hamartomatous, neoplastic, or congenital malformative origin [6] [7]. The condition is often associated with different types of malformation such macrocephaly, megacephaly, syringomyelia, polydactyly, multiple haemangiomas and mucocutaneous lesions as well as breast, thyroid, genitourinary and gastrointestinal malignancies [8]. This has suggested a genetic correlation between LDD and Cowden's syndrome, an autosomal dominant syndrome characterised by a genetic aberration and multiple hamartomas and tumors of endodermal origin, mesodermal and ectodermal [9]. About $40 \%$ of cerebellar dysplastic gangliocytoma occur as part of Cowden disease [10]. For this reason, patients with LhermitteDuclos disease should be actively investigated for this syndrome [10] [11]. 


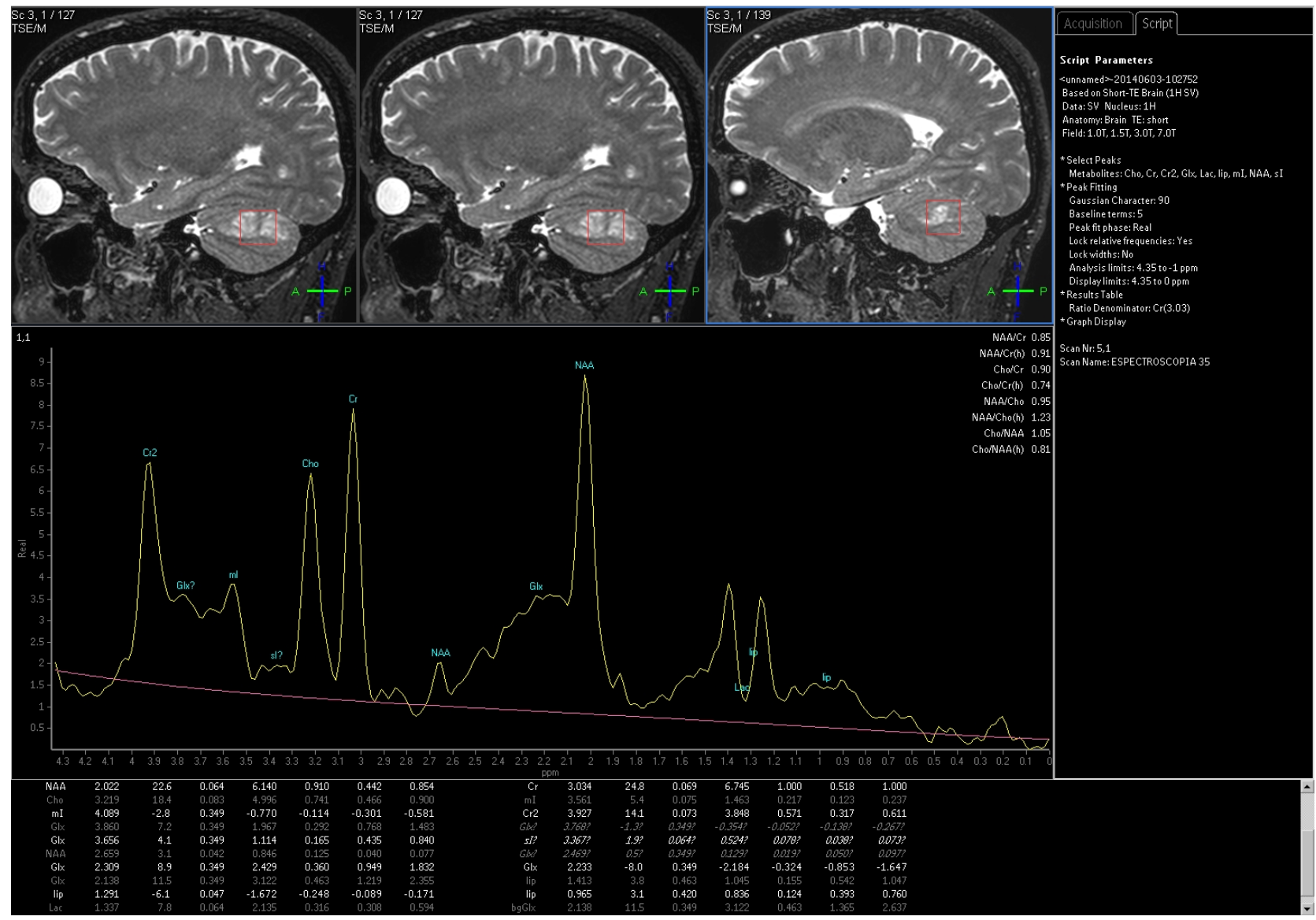

Figure 5. Multivoxel Proton MR Spectroscopy demonstrating maintenance of the peaks of NAA, Cho, MI and Cr.

With the help of computed tomography, we can identify a nodular focal lesion, usually unique, located in one of the cerebellar hemispheres, iso/low attenuation, which may rarely contain calcification foci inside, without evident enhancement by iodinated contrast media and can determine thinning of the cranial capin correspondence [4].

Magnetic resonance imaging is the imaging test of choice for the diagnosis of Lhermitte-Duclos disease, featuring slightly heterogeneous morphological change, evidenced by thickening of the cerebellar folia, promoting mass effect and exhibiting linear bands with hypointense on T1 and alternating inner layers hyperintense and external hypointense on $\mathrm{T} 2$, resulting, in the latter consideration, in a typical striated pattern, which sets the cerebellar tissue the appearance of "tiger stripes" [1] [9] [12].

The $\mathrm{T}^{*}$ (GRE SWI) shows prominent vascular channels surrounding cerebellar folias without evidence of distortion of its path. The identification of the anatomical structures and veins is better in 7T MR than 1.5T MR due to the increased signal-to-noise ratio. Susceptibility weighted imaging (SWI) can demonstrate in greater detail small veins and depict large draining veins and the cerebellar nuclei, bringing useful information for surgical planning [13].

Usually there is no enhancement of paramagnetic contrast agent on the injury, showing no breakdown of the blood brain barrier, although in some cases it can 
be observed marked linear enhancement in prominent abnormal veins [2] [14]. The diffusion sequence shows areas of hypersignal, without correlation with areas of signal loss on the ADC map, not demonstrating true restriction to water molecules motion, but a T2 shine through. Some cases with restricted diffusion within LDD lesion has been reported and likely reflects hypercellularity and dense collection of axons [15].

Although our case did not show areas of higher perfusion, some case reports have shown it [15]. Studies using nuclear medicine, xenon-CT and PWI have shown an elevated metabolic rate [3] [14]. Spectroscopy MRI shows peak normal NAA or slightly reduced, and choline relationship: regular creatine [2]. These vascular and metabolic profiles are consistent with a lesion with growth potential, but the MR-spectroscopy reports normal Cho/Cr ratios in LDD, due to the absence of significant membranes' turnover. These complex imaging findings are in line with the debate around the origin of LDD [15].

Sequences of diffusion and magnetic resonance spectroscopy are important for the differential diagnosis [16] [17].

Lhermitte-Duclos presents itself as a single lesion, in addition to cerebellar infarction, which follows the path of the cerebellar folia, despite promoting their extension.

The differential diagnosis of cerebellar dysplastic gangliocytoma is diffuse astrocytoma and desmoplastic medulloblastoma. Diffuse astrocytoma differs by more homogeneous signal change, with foci of abnormal gadolinium uptake and standard magnetic resonance spectroscopy demonstrating elevation of myoinositol in low-grade and elevated choline and lactate in high-grade lesions. The desmoplastic medulloblastoma, adult hemispherical variant presents real restriction on passive diffusivity of water molecules, high choline levels, reducing the peak of NAA to proton spectroscopy and alteration of vascular paths within the lesion to magnetic susceptibility sequence SWI [16] [17].

\section{Conclusion}

In conclusion, Lhermitte-Duclos disease, although rare, presents quite characteristic MRI findings that allow differentiating it with a high degree of accuracy of its main differential diagnosis, enabling the monitoring of injury without performing unnecessary invasive diagnostic procedures.

\section{References}

[1] Nowak, D.A. and Trost, H.A. (2002) Lhermitte-Duclos Disease (Displastic Cerebellar Gangliocitoma): A Malformation Hamartoma or Neoplasm? Acta Neurologica Scandinavica, 105, 137-145.

[2] Carlson, J.J., Milburn, J.M. and Barré, G.M. (2006) Lhermitte-Duclos Disease: Case Report. Journal of Neuroimaging, 16, 157-162. https://doi.org/10.1111/j.1552-6569.2006.00020.x

[3] Klisch, J., Juenglinga, F., Spreera, J., Kocha, D., Thiela, T., Bücherta, M., Arnolda, S., Feuerhakea, F. and Schumachera, M. (2001) Lhermitte-Duclos Disease: Assessment with MR Imaging, Positron Emission Tomography, Single-Photon Emission CT, 
and MR Spectroscopy. American Journal of Neuroradiology, 22, 824-830.

[4] Koeller, K.K. and Henry, J.M. (2001) Superficial Gliomas: Radiologic-Pathologic Correlation. Radiographics, 21, 1533-1556.

https://doi.org/10.1148/radiographics.21.6.g01nv051533

[5] Giorgianni, A., Pellegrino, C., De Benedictis, A., et al. (2013) Lhermitte-Duclos Disease: A Case Report. The Neuroradiology Journal, 26, 655-660. https://doi.org/10.1177/197140091302600608

[6] Miller, C. (2002) Cowden Disease (Multiple Hamartoma Syndrome). In: Elmets, C., Vinson, R., Libow, L., Quirk, C., James, W.W., et al., Eds., eMedicine Instant Access to the Minds of Medicine, LU, Institute for Healthcare Improvement, USA. http://emedicine.medscape.com/

[7] Buhl, R., Barth, H., Hugo, H.H., et al. (2003) Dysplastic Gangliocytoma of the Cerebellum: Rare Differential Diagnosis in Space Occupying Lesions of the Posterior Fossa. Acta Neurochirurgica, 145, 509-512.

[8] Patel, S. and Barkovich, A.J. (2002) Analysis and Classification of Cerebellar Malformations. American Journal of Neuroradiology, 23, 1074-1087.

[9] Karezi, C., Boutarbouch, M., Coulibaly, O., Derraz, S., El Ouahabi, A. and El Khamlichi, A. (2013) Acute Hydrocephalus Revealing Unusual Cerebellar Mass: Dysplastic Cerebellar Gangliocytoma or Lhermitte-Duclos Disease (LDD). Neurocience and Medicine, 4, 161-165. https://doi.org/10.4236/nm.2013.43026

[10] Murray, C., Shipman, P., Khangure, M., et al. (2001) Lhermitte-Duclos Disease. Australasian Radiology, 45, 343-346. https://doi.org/10.1046/j.1440-1673.2001.00933.x

[11] Williams, D.W., Elster, A.D., Ginsberg, L.E., et al. (1994) Recurrent LhermitteDuclos Disease: Report of Two Cases and Association with Cowden's Disease. Neurology, Neurosurgery and Psychiatry, 57, 699-704.

[12] Smith, R.R., Grossman, R.I., Goldberg, H.I., Hackney, D.B., Bilaniuk, L.T. and Zimmerman, R.A. (1989) MR Imaging of Lhermitte-Duclos Disease: A Case Report. American Journal of Neuroradiology, 10, 187-189.

[13] Moeninghoff, C., Kraff, O., Schalamann, M., et al. (2010) Assessing a Dysplastic Cerebellar Gangliocytoma (Lhermitte-Duclos Disease) with 7TMR Imaging. Korean Journal of Radiology, 11, 244-248. https://doi.org/10.3348/kjr.2010.11.2.244

[14] Spaargaren, L., Cras, P., Bomhof, M.A.M., Lie, S.T., Barsy, A.M., Croese, P.H., Teepen, J.L.J., Duwel, V.H.J.M., Van Goethem, J.W., Ozsarlak, O., Van den Hauwe, L., De Schepper, A.M. and Parizel, P.M. (2003) Contrast Enhancement in Lhermitte-Duclos Disease of the Cerebellum: Correlation of Imaging with Neuropathology in Two Cases. Neuroradiology, 45, 381-385.

https://doi.org/10.1007/s00234-003-0984-2

[15] Cianfoni, A., Wintermark, M., Piludu, F., D’Alessandris, Q.G., Lauriola, L., Visocchi, M. and Colosimo, C. (2008) Morphological and Functional MR Imaging of Lhermitte-Duclos Disease with Pathology Correlate. Journal of Neuroradiology, 35, 297-300.

[16] Rocha, A.J., Vedolin, L. and Mendonça, R.A. (2012) Encéfalo (série CBR). Elsevier, São Paulo, 350-365.

[17] Housni, A. and Boujraf, S. (2012) Magnetic Resonance Spectroscopy in the Diagnosis and Follow-Up of Brain Tumors. Journal of Biomedical Science and Engineering, 5, 853-861. https://doi.org/10.4236/jbise.2012.512A108 
Submit or recommend next manuscript to SCIRP and we will provide best service for you:

Accepting pre-submission inquiries through Email, Facebook, LinkedIn, Twitter, etc. A wide selection of journals (inclusive of 9 subjects, more than 200 journals)

Providing 24-hour high-quality service

User-friendly online submission system

Fair and swift peer-review system

Efficient typesetting and proofreading procedure

Display of the result of downloads and visits, as well as the number of cited articles Maximum dissemination of your research work

Submit your manuscript at: http://papersubmission.scirp.org/

Or contact nm@scirp.org 